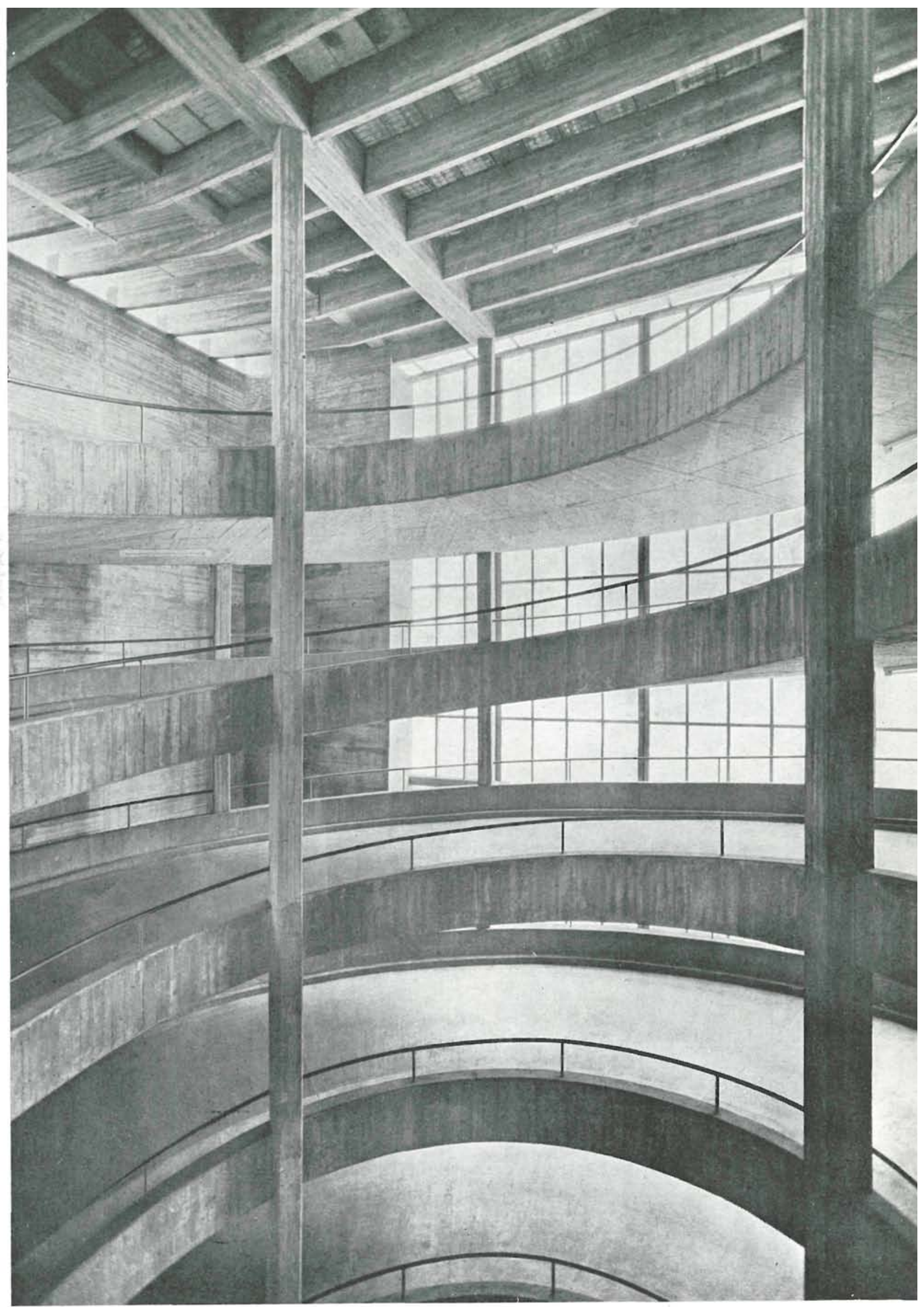

$138-21$

\title{
garaje, en Frankfurt
}

MAX MEID, HELMUT ROMEICK y VOLKER WAGNER, arquitectos 


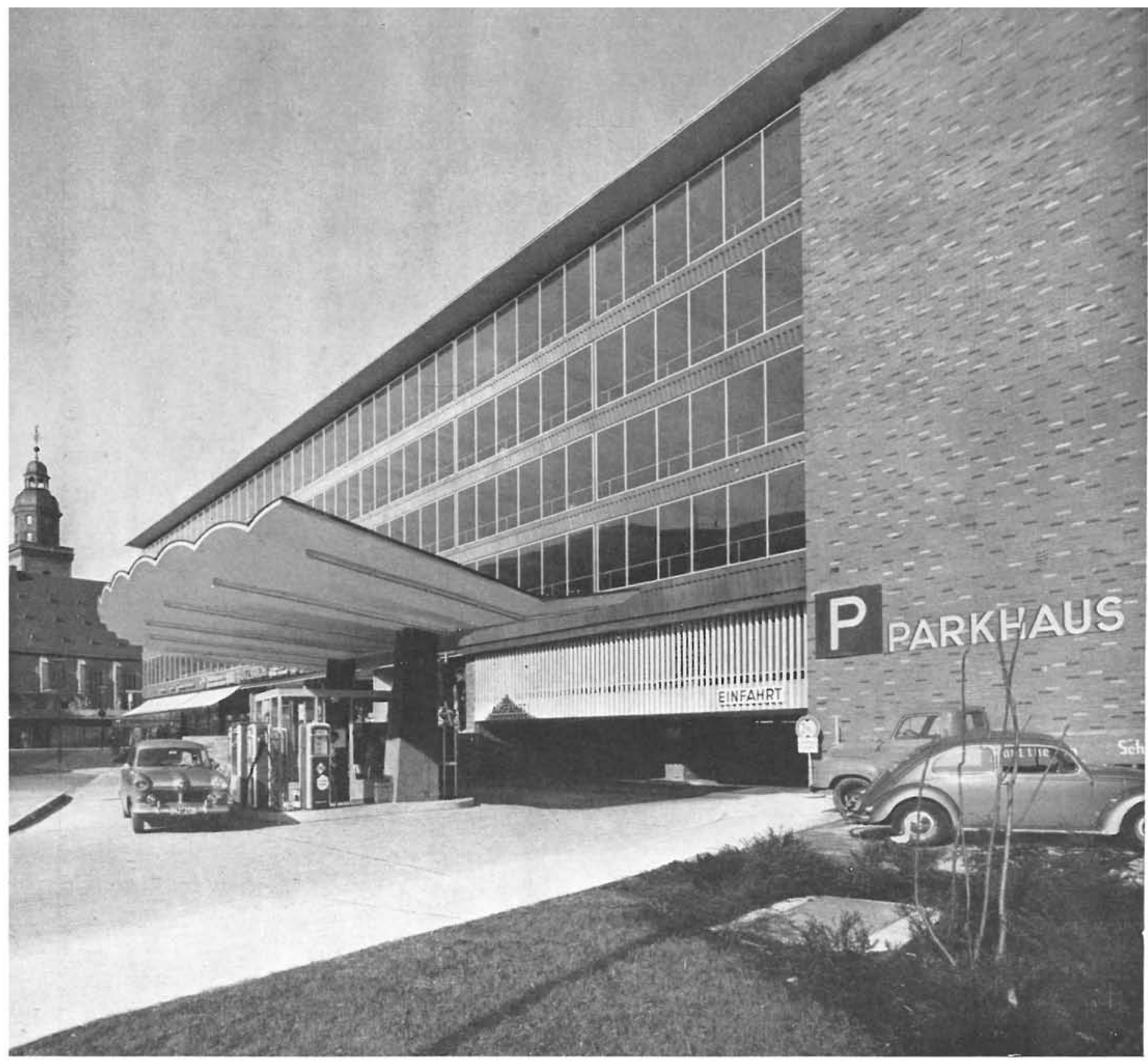

Detalle de la gasolinera y perspectiva del conjunto.

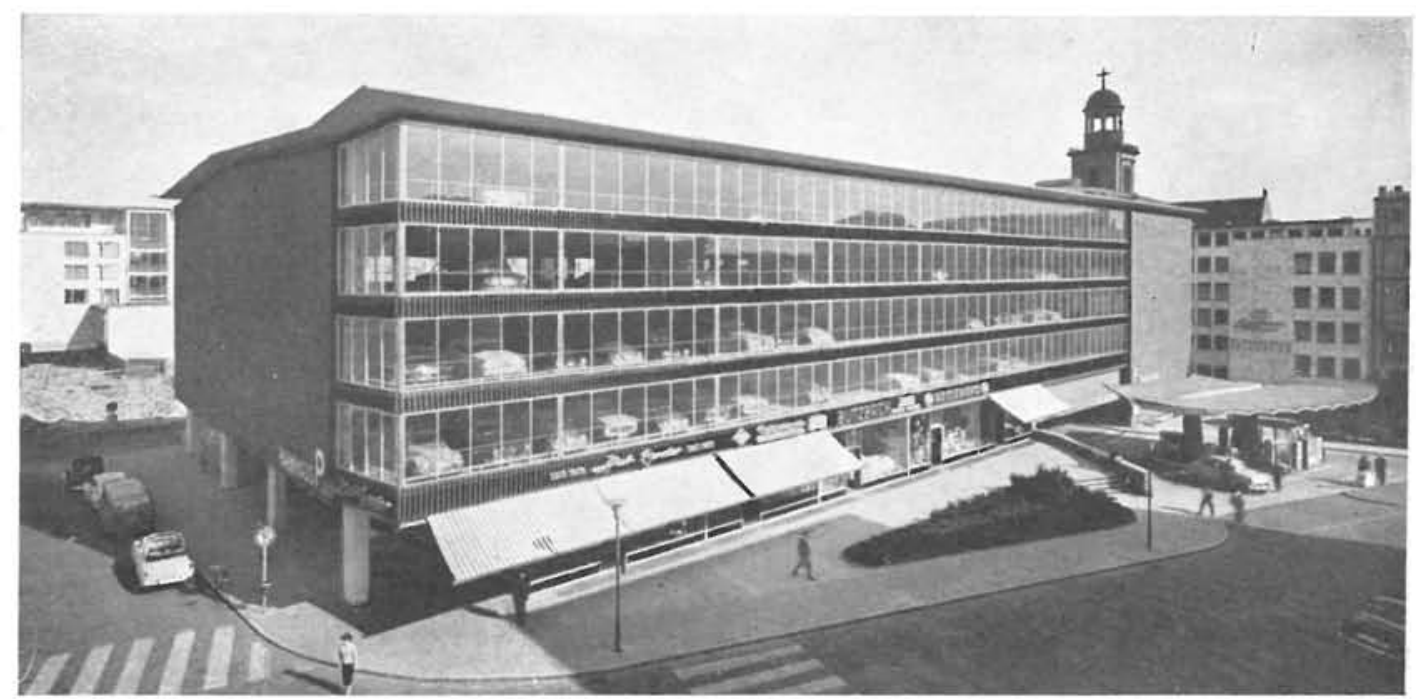




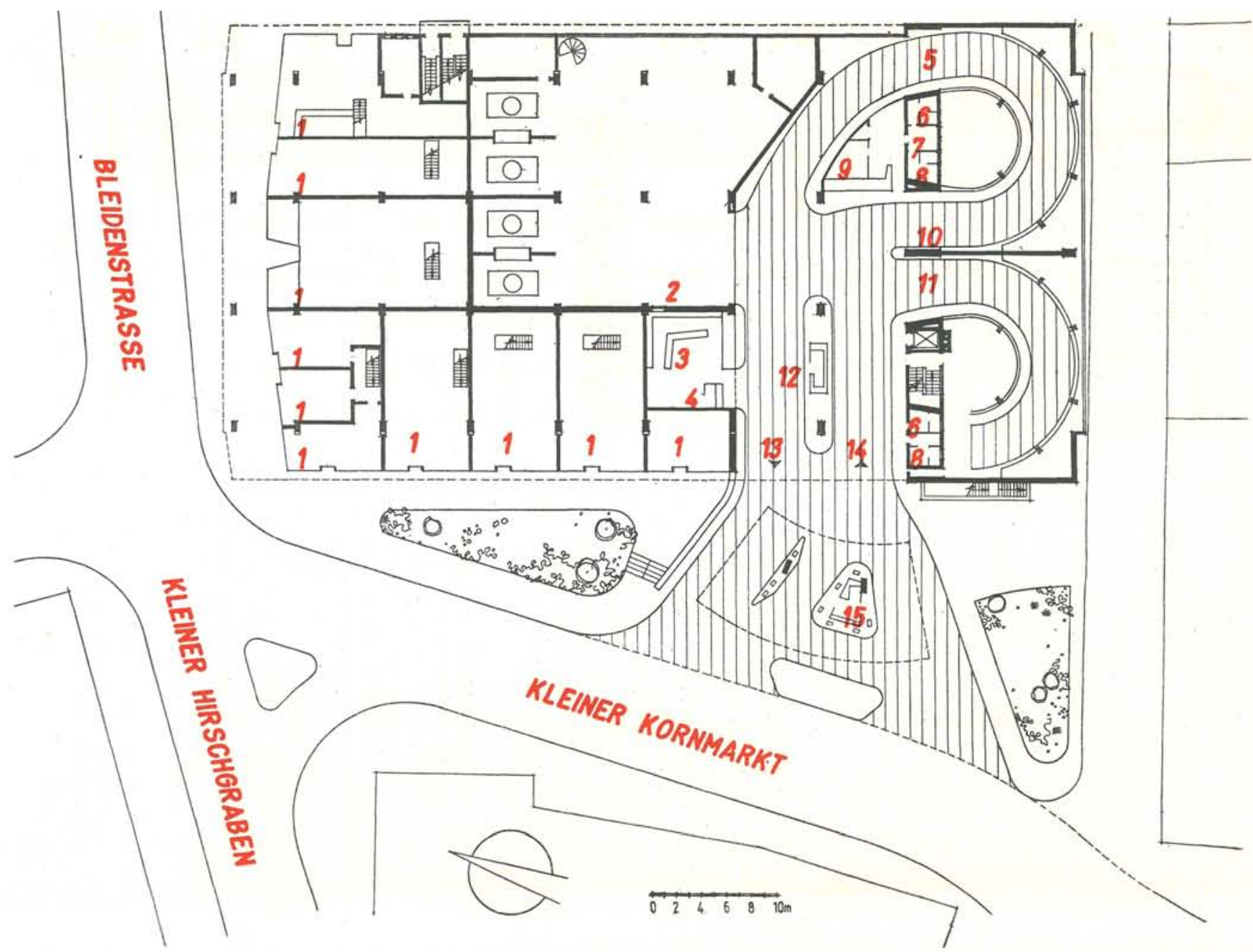

planta baja

planta tipo

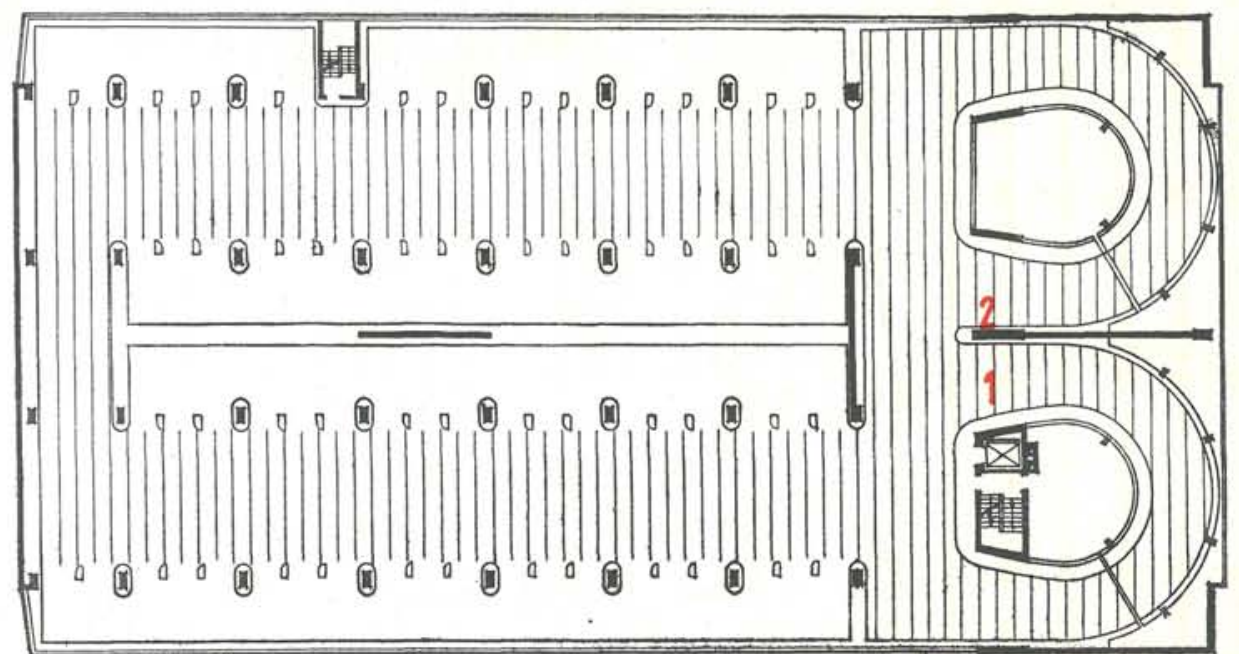

1. Tiendas, -2 . Lavado $y$ engra. se, -3 . Contador. 4. Caja, -5. Saliforas, $\rightarrow$. Vestua

rio. -8 . Aseo caballeros. -9 . Administracion. -

do hacia el sota.

no. -11. Acceso.-
12 . Control. -13 .

Satida. - 14. En-

trada. -15 . Esta-
cłón de servicio.

1. Entrada. 


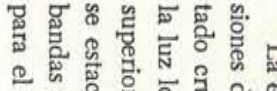
내유.

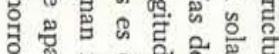
के क्षै

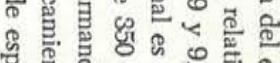
苋.

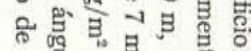

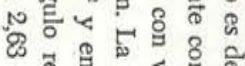

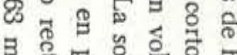

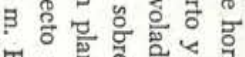

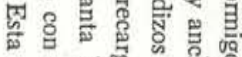

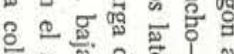
函.

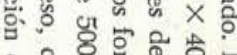
8 염 졀 Ш

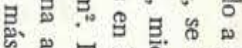

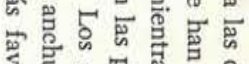

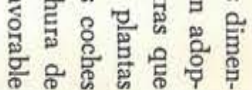

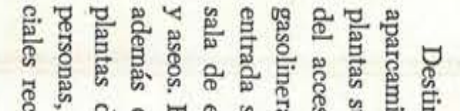

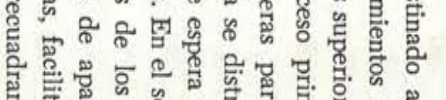

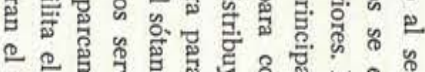

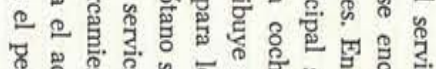

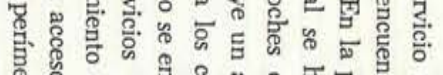

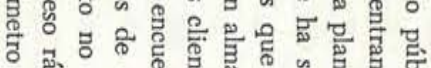

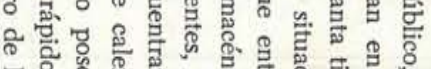

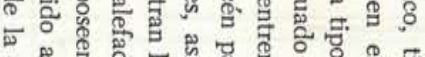

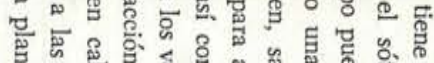

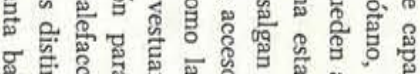

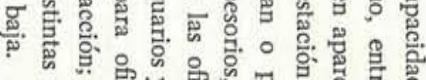

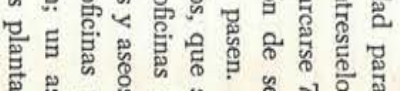

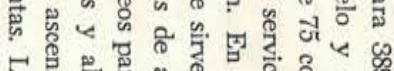

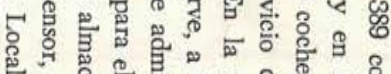

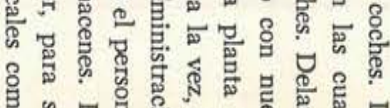

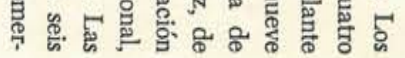
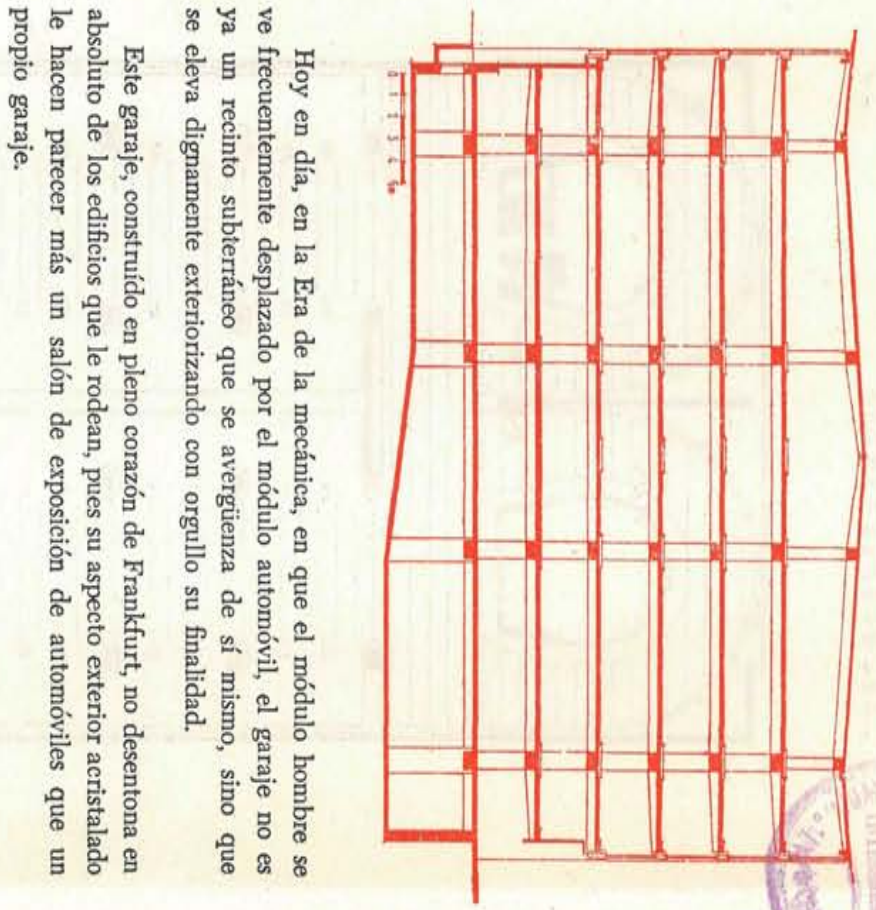

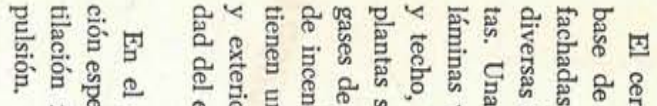

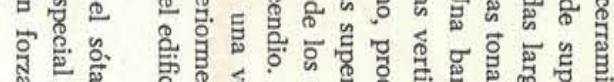

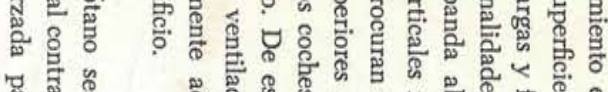
與

क

वृ

ลำ 몀

ฉ
\% है. कू

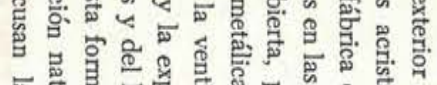

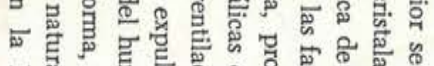

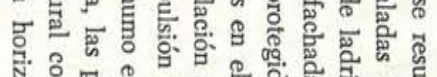

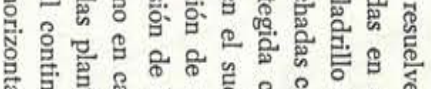

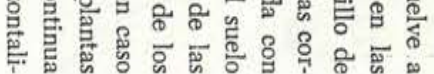

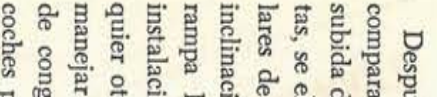

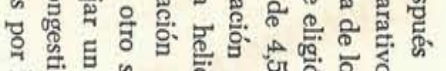

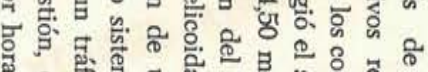

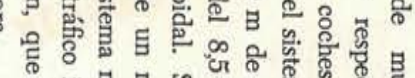
政责

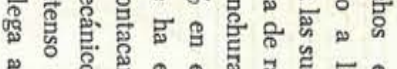

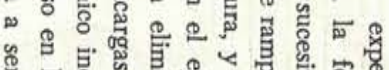

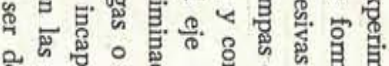

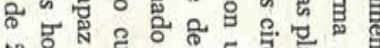

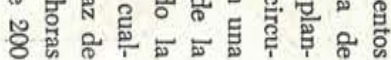

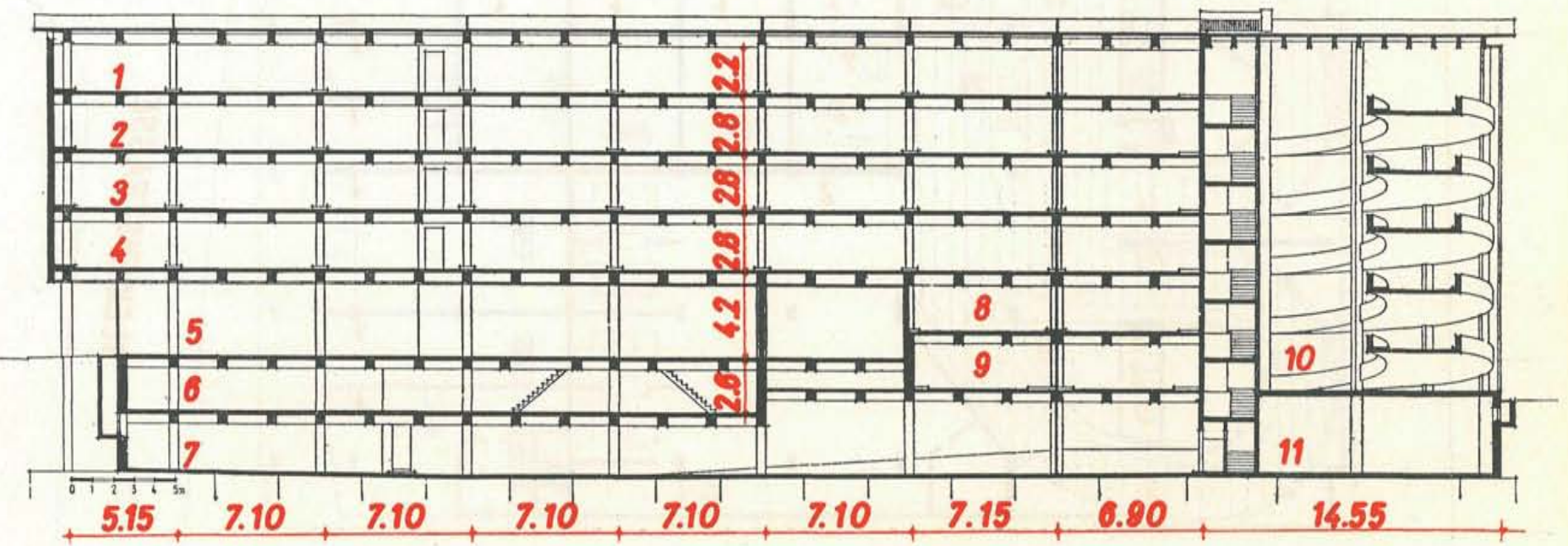




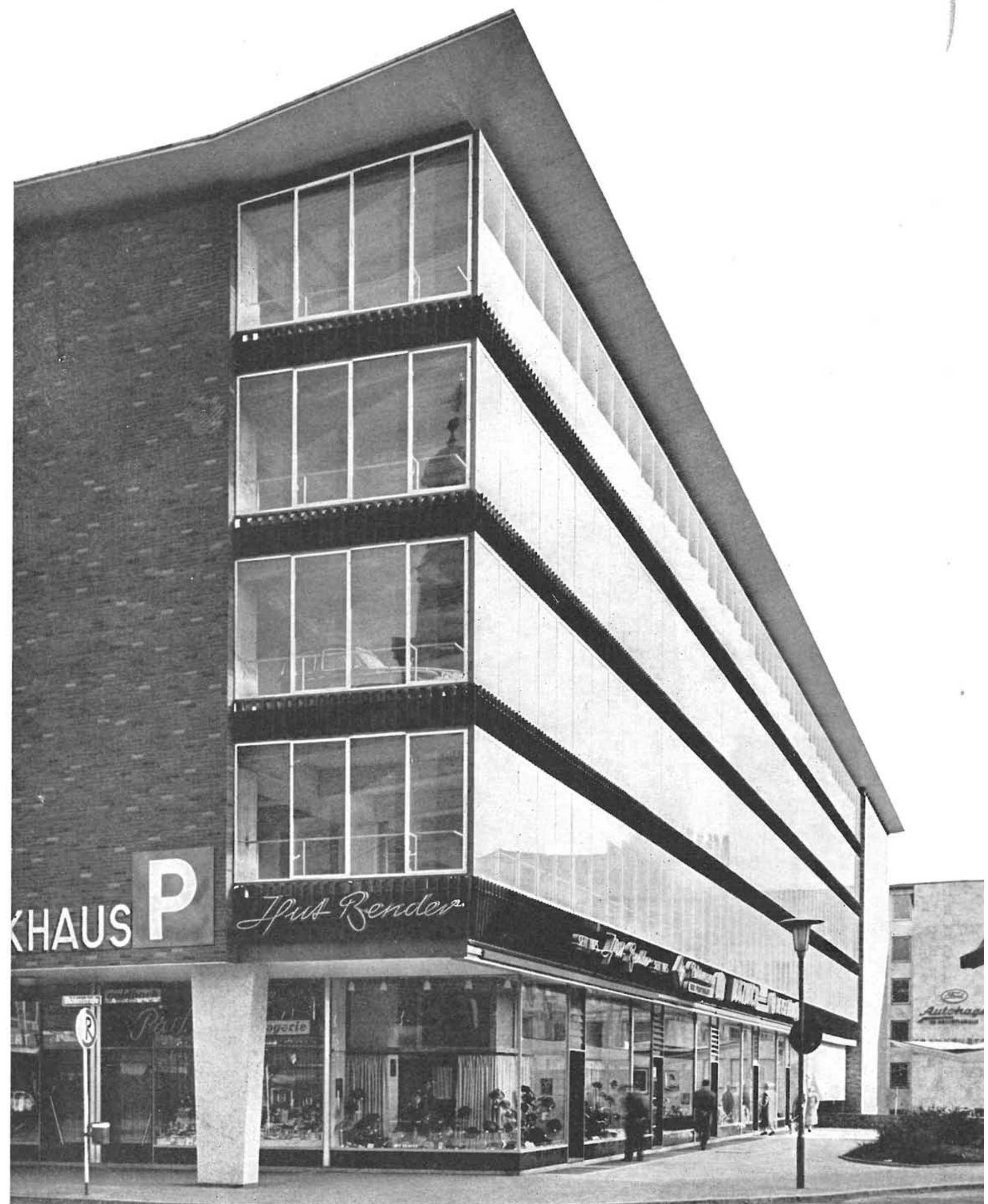


El hormigón queda visto al interior, en todos sus elementos estructurales, contrastando con las grandes superficies de cristal, que se limpian por medio de una grúa exterior.

Las plantas del sótano se alquilan permanentemente y las demás plantas se dedican al aparcamiento por horas. El cliente tiene a la entrada una taquilla, donde, sin bajarse del coche, recibe un talón en el que se registra la hora de llegada. Asciende por la rampa y aparca en el lugar indicado; una vez aparcado, baja en el ascensor hasta la planta baja.

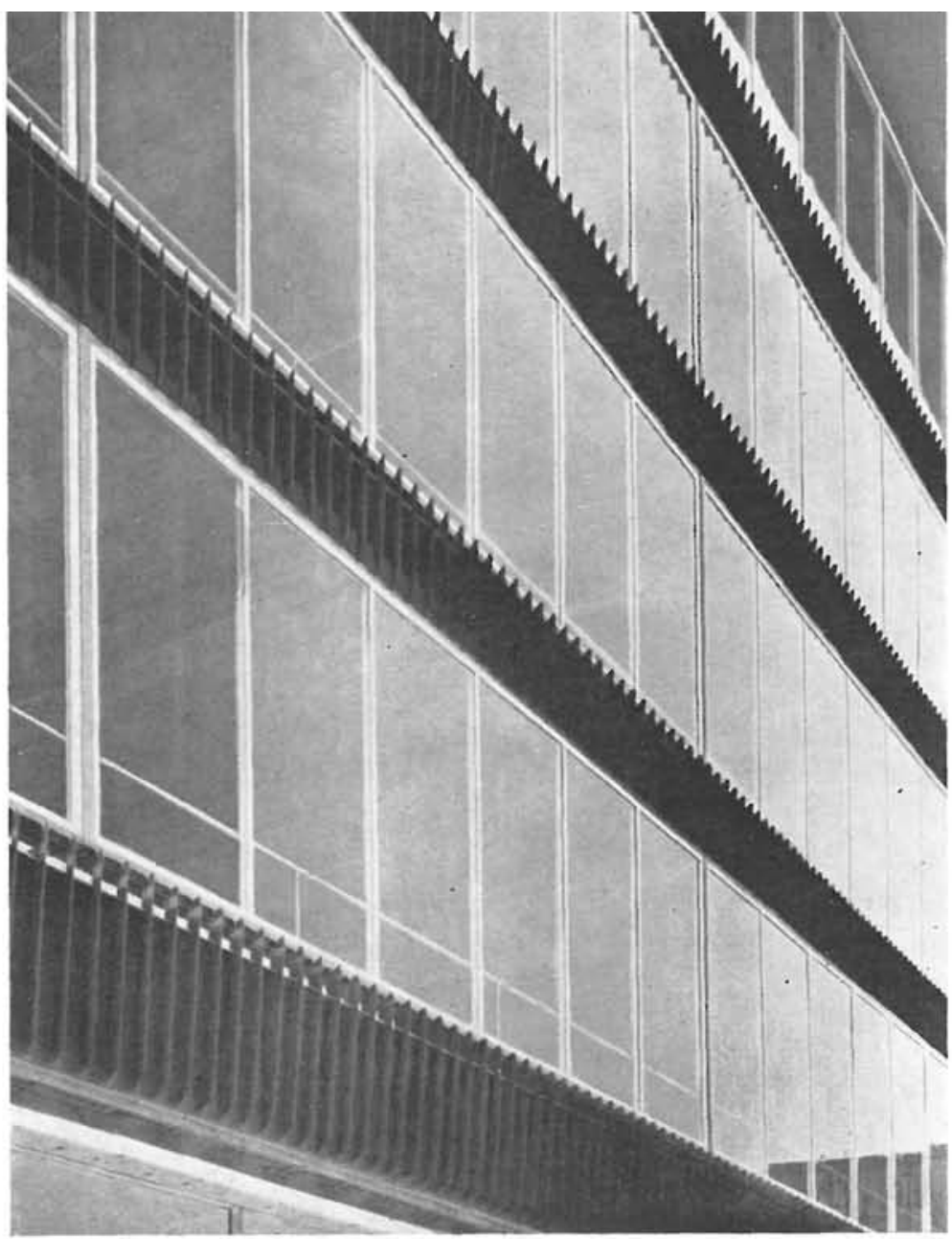

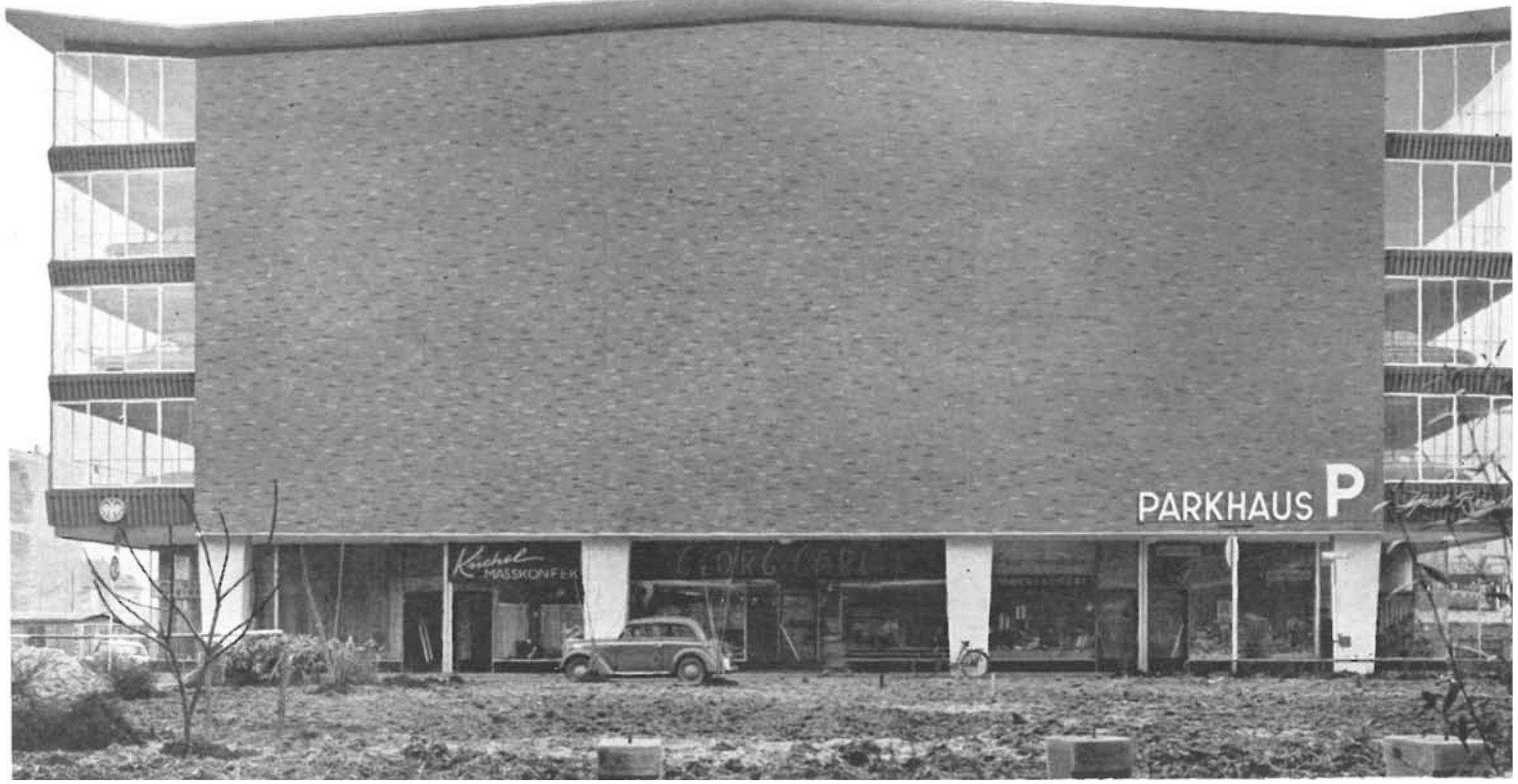




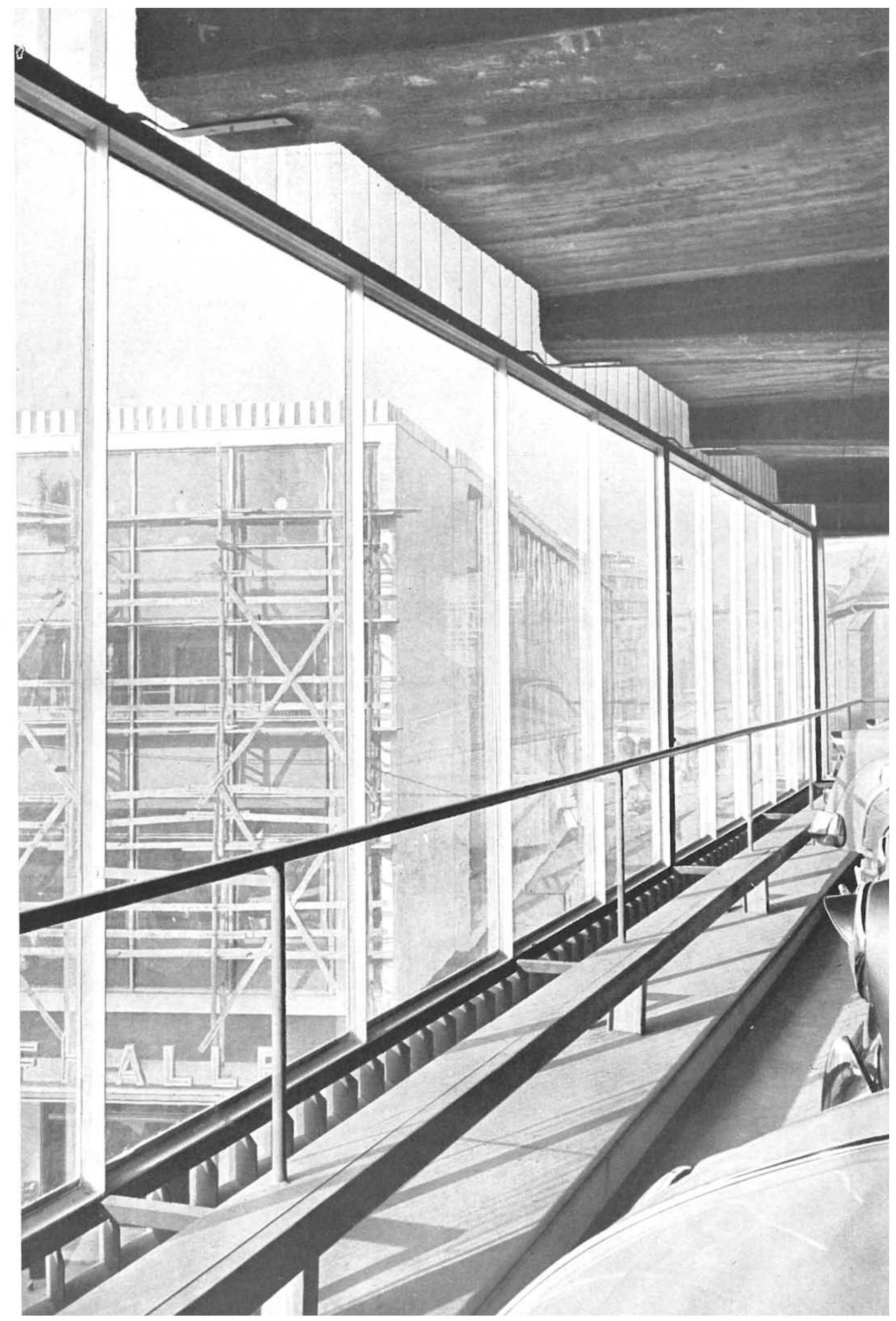




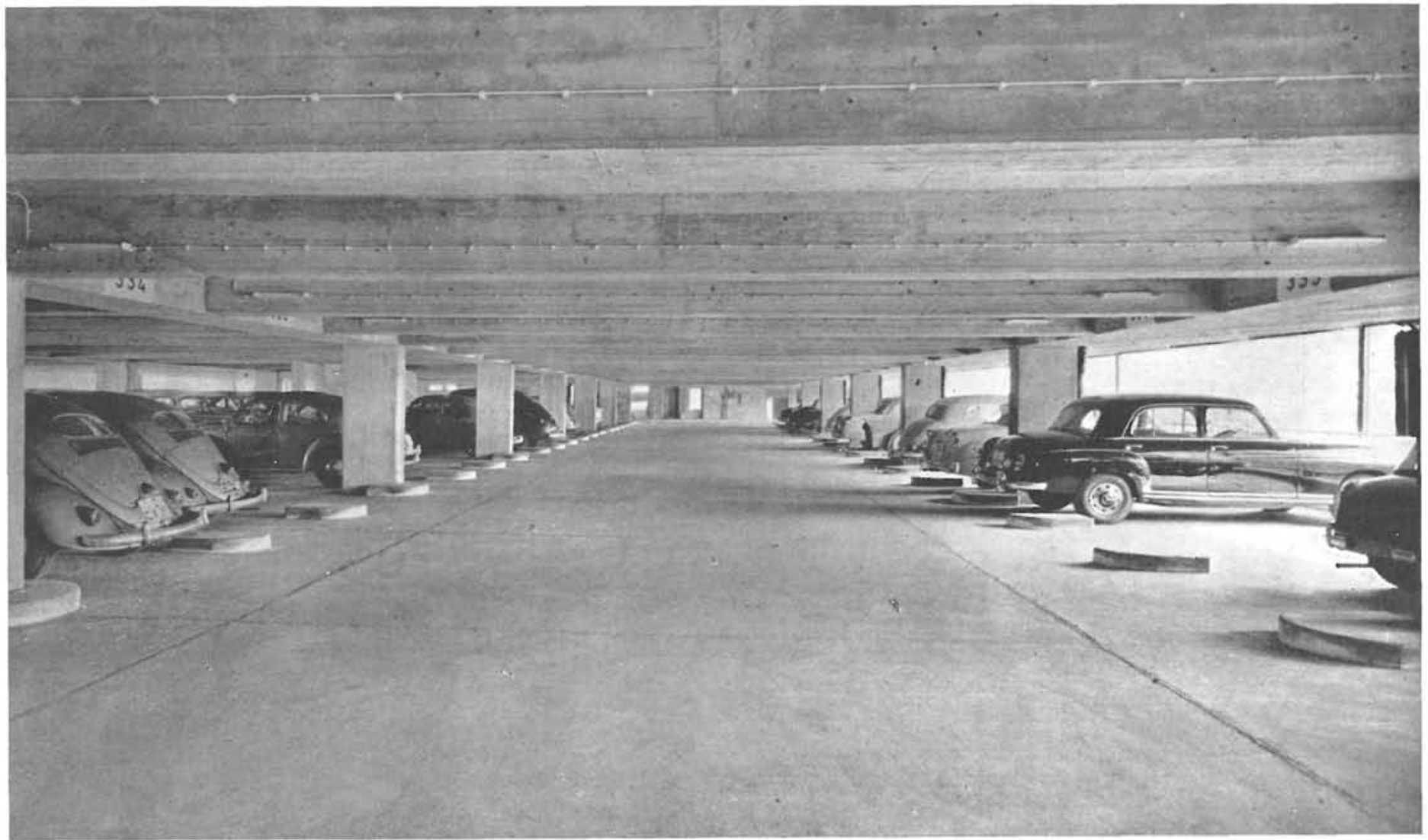

Fotos: WILFRIED WOSCIDIO y BILDERDIENST GRIESHABER

$\mathrm{Al}$ ir a recoger su coche, paga primero la tarifa con arreglo al tiempo que ha durado su aparcamiento; sube en el ascensor; recoge su automóvil, y al llegar a la salida, también sin bajarse del coche, devuelve su recibo pagado.

Los tráficos de acceso, tanto de entrada como de salida, son de dirección única, ya que hay una rampa de subida y otra de bajada. Sólo al llegar a la estación de servicio existen los cruces de circulaciones, pero con la señalización existente no ha habido hasta ahora perturbaciones.

La estación de servicio, con su gran bóveda laminar de hormigón armado, contrasta con el resto del conjunto, rompiendo con sus ondas la frialdad de las líneas rectas que dominan la composición del edificio.

I N F O R M E S D D E L A C C O N S T R U C C I O N 